GCA Technical Report No. 65-26-N
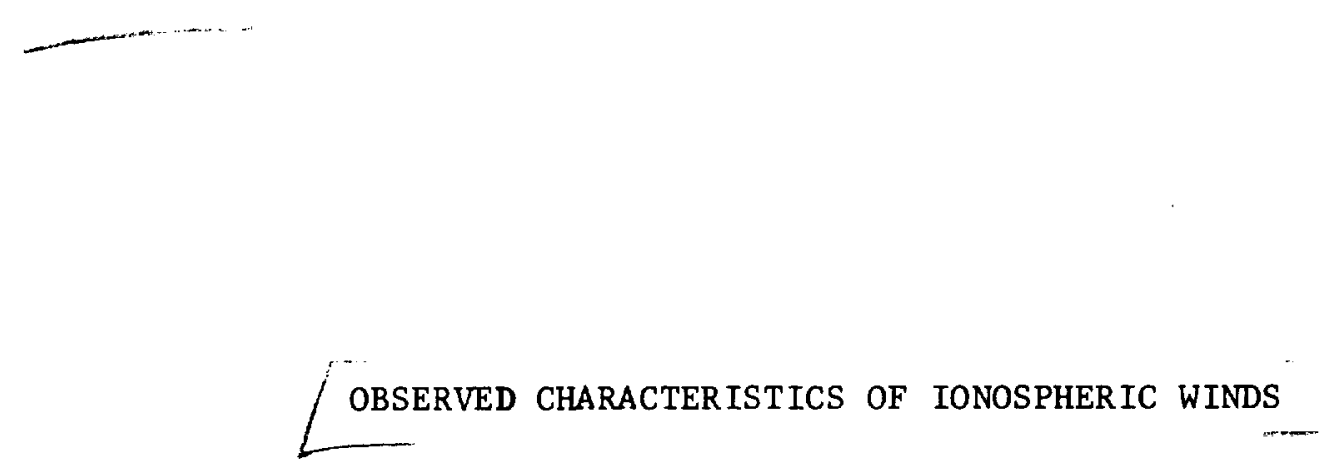

J. F. Bedinger and H. B. Knaflich

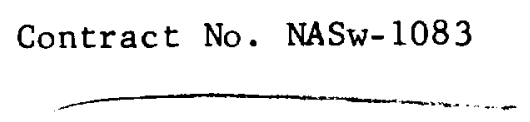

August 1965

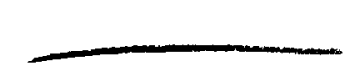

GCA CORPORATION

GCA TECHNOLOGY DIVISION

Bedford, Massachusetts

Prepared for

NATIONAL AERONAUTICS AND SPACE ADMINISTRATION

Headquar ters

Washington, D. C. 


\section{ABSTRACT}

10958

The general characteristics of ionospheric winds during twilight have been determined from observations of the motion and growth of sunlit trails of alkali vapor. Typical large shears and small features are described. Specific wind profiles are compared with nearly simultaneous measurements of electron concentration from rocket-borne probes. Generally, the narrow regions of enhanced electron concentration measured by the probes do not occur in the low velocity region of an $E-W$ shear. However, the ionization peaks appear to be associated with certain other features of the wind profile.

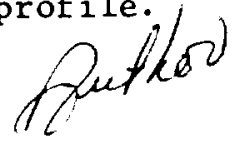




\section{•}


TABLE OF CONTENTS

Title

ABSTRACT

INTRODUCTION

OBSERVED WIND STRUCTURE

CORRELATION OF WINDS AND PEAKS OF ELECTRON DENS ITY

REFERENCES
Page

i

1

3

9

27 
. 


\section{LIST OF ILLUSTRATIONS}

$\underline{\text { Figure }}$

$\underline{\text { Title }}$

Page

1 The photographs on the left were taken at Wallops Island, Virginia during morning twilight on 17 September 1961 at 300 seconds after launch, and on 17 April 1962 at $280 \mathrm{sec}-$ onds after launch. The vertical wind profiles are shown to the right in the form of polar plots. Each solid dot represents a height interval of $1 \mathrm{~km}$; each open dot represents a height interval of $5 \mathrm{~km}$. The ends of these vectors are joined consecutively in height by a solid line. Only the height for every $5 \mathrm{~km}$ intervals is indicated. The crosses indicate the wind speed scale in $\mathrm{m} / \mathrm{sec}$.

Rate and frequency of occurrences of shears for $10 \mathrm{~km}$ height intervals.

The photograph on the left was taken with a 36 inch focal length camera from Dover, Delaware during morning twilight of 16 January 1964 at 212 seconds after launch. Heights from 98 to $111 \mathrm{~km}$ are indicated. To the right, the rate of growth of the globule located at a height of $104 \mathrm{~km}$ is shown.

Geomagnetic East-West and North-South wind speed components versus height for 7 November 1962 at 0553 EST. Regions of enhanced electron density are marked by arrows on both components. The winds were observed 28 minutes after the electron density with a horizontal separation of $24 \mathrm{~km}$.

Geomagnetic East-West and North-South wind speed components versus height for 30 November 1962 at 0615 EST. Regions of enhanced electron density are marked by arrows on both components. The winds were observed 18 minutes after the electron density with a horizontal separation of $21 \mathrm{~km}$.

Geomagnetic East-West and North-South wind speed components versus height for 5 December 1962 at 1716 EST. Regions of enhanced electron density are marked by arrows on both components. The winds were observed 14 minutes after the electron density with a horizontal separation of $41 \mathrm{~km}$. 

LIST OF ILLUSTRATIONS (continued)

$\underline{\text { Figure }}$

$\underline{\text { Title }}$

$\underline{\text { Page }}$

7

Geomagnetic East-West and North-South wind speed components versus height for $15 \mathrm{July} 1964$ at $0305 \mathrm{EST}$. Regions of enhanced electron density are marked by arrows on both components. The winds were observed about 2 minutes after the electron density with a horizontal separation of $66 \mathrm{~km}$.

8 Geomagnetic East-West and North-South wind speed components versus height for $15 \mathrm{July} 1964$ at 0406 EST. Regions of enhanced electron density are marked by arrows on both components. The winds were observed 14 minutes before the electron density with a horizontal separation of $93 \mathrm{~km}$.

Geomagnetic East-West and North-South wind speed components versus height for 7 October 1964 at 1808 EST. Regions of enhanced electron density are marked by arrows on both components. The winds were observed 4 minutes after the electron density with a horizontal separation of $107 \mathrm{~km}$.

Geomagnetic East-West and North-South wind speed components versus height for 8 October 1964 at 0527 EST. Regions of enhanced electron density are marked by arrows on both components. The winds were observed 4 minutes after the electron density with a horizontal separation of $80 \mathrm{~km}$.

11 A polar plot of the wind profile for 7 November 1962 appears in the center. Solid dots mark the ends of the wind vectors for each $\mathrm{km}$ in height. The open circles indicate each $5 \mathrm{~km}$ height interval and are the only ones which show the height. The crosses indicate the wind speed scale in $\mathrm{m} / \mathrm{sec}$. Regions of enhanced electron density are marked by arrows. Each region of enhanced electron density is shown on a double wind speed scale. The dashed lines around the arrows represent the general region covered by the electron enhancement. The geographical compass directions are shown at the bottom of the figure. 


\section{LIST OF ILLUSTRATIONS (continued)}

Figure

12

Title

Page

A polar plot of the wind profile for 30 November 1962 is shown. The solid dots mark the ends of the wind vector for each $\mathrm{km}$ in height, and the open circles are for every $5 \mathrm{~km}$. The crosses represent the wind speed scale in $\mathrm{m} / \mathrm{sec}$. The arrows indicate regions of maximum enhanced electron density, while the dotted lines encompass the whole area.

A polar plot of the wind profile for 5 December 1962 appears in the center. Solid dots mark the ends of the wind vectors for each $\mathrm{km}$ in height. The open circles indicate each $5 \mathrm{~km}$ height interval and are the only ones which show the height. The crosses indicate the wind speed scale in $\mathrm{m} / \mathrm{sec}$. Regions of enhanced electron density are marked by arrows. The two regions of enhanced electron density are shown separately to the side on the same scale. The dashed lines around the arrows represent the general region covered by the electron enhancement. The geographical compass directions are shown at the bottom of the figure.

A polar plot of the wind profile for 15 July 1964 at 0305 EST is shown. Since this was a night shot the sodium cloud appeared only between the heights of 107 to 119.4 $\mathrm{km}$. The solid dots mark the ends of the wind vectors with the accompanying heights. The crosses indicate the wind speed scale in $\mathrm{m} / \mathrm{sec}$. The arrow represents the position of the maximum electron density peak at $119 \mathrm{~km}$. The dashed line shows the general region covered by the electron enhancement, and is shown incomplete due to the wind profile limitations.

A polar plot of the wind profile for $15 \mathrm{July} 1964$ at 0406 EST appears in the center. Solid dots mark the ends of the wind vectors for each $\mathrm{km}$ in height. The open circles indicate each $5 \mathrm{~km}$ height interval and are the only ones which show the height. The crosses indicate the wind speed scale in $\mathrm{m} / \mathrm{sec}$. Regions of enhanced electron density are marked by arrows. The two regions of enhanced electron density are shown separately to the side on the same scale. The dashed lines around the arrows represent the general region covered by the electron enhancement. The geographical compass directions are shown at the bottom of the figure. 
$\ddots$ 
A polar plot of the wind profile for 7 October 1964 appears in the center. Solid dots mark the ends of the wind vectors for each $\mathrm{km}$. The open circles indicate each $5 \mathrm{~km}$ interval and are the only ones showing height. The crosses indicate the wind speed scale in $\mathrm{m} / \mathrm{sec}$. Arrows indicate regions of enhanced electron density. The two regions of enhanced electron density are shown separately to the side on the same scale. The dashed lines around the arrows represent the general region covered by the electron enhancement. The geographical compass directions are shown at the bottom of the figure.

17 A polar plot of the wind profile for 8 October 1964 appears in the center. Solid dots mark the ends of the wind vectors for each $\mathrm{km}$. The open circles indicate each $5 \mathrm{~km}$ interval and are the only ones showing height. The crosses indicate the wind speed scale in $\mathrm{m} / \mathrm{sec}$. Arrows indicate regions of enhanced electron density. The two regions of enhanced electron density are shown separately to the side on the same scale. The dashed lines around the arrows represent the general region covered by the electron enhancement. The geographical compass directions are shown at the bottom of the figure. 


\title{
OBSERVED CHARACTERISTICS OF IONOSPHERIC WINDS
}

\author{
By J. F. Bedinger and H. B. Knaflich \\ GCA Corporation
}

\author{
INTRODUCTION
}

The vapor trail method of measuring ionospheric winds during twilight has been used at Wallops Island, Virginia since $1959[1,2]^{\star}$. Observations from 29 different twilight trails have been used to determine the magnitude and frequency of occurrence of large scale shears and some small scale phenomena in the region 80 to $130 \mathrm{~km}$. It was found that shears greater than $50 \mathrm{~m} / \mathrm{sec} / \mathrm{km}$ are not usually present but sometimes occur in the 100 to $110 \mathrm{~km}$ region.

Measurements of electron concentration [3] were made nearly simultaneously with seven of these wind observations. Detailed comparisons of the wind profiles have been made with narrow regions of increased electron density as measured by the Langmuir probe. The peaks on the electron density profile appear to be randomly scattered with respect to wind shears. In many cases, these peaks are more closely associated with other features on the wind profile.

\footnotetext{
* Numbers in [ ] through the text represent reference numbers.
} 



\section{OBSERVED WIND STRUCTURE}

The general character of the ionospheric winds has often been described as irregular or turbulent. However, there are certain features as evidenced by vapor trails which occur regularly. Some of the more regular features are illustrated in Figure 1, in which two different vapor trails are shown together with the vertical wind profile derived from each. The wind profiles are displayed on polar plots on which solid dots mark the tips of vectors representing the wind velocity at $1 \mathrm{~km}$ height intervals, and open dots represent the velocity at $5 \mathrm{~km}$ height intervals. These vectors are joined consecutively in height by a solid line.

One of the wind profiles exemplifies a group of observations in which the direction of the wind continually rotates in a clockwise manner with height. About one third of the observations belong to this group. The other profile in Figure 1 shows a reversal in direction of rotation. A tendency for counter clockwise rotations in some height regions is apparent in about one third of the observed profiles. In both of these profiles it is seen that wind speeds as well as changes in wind speed and direction may be large. The remaining one third of the observations show no such distinctive features. The winds are not strong and are variable in both speed and direction.

The direction and magnitude of the total shear is clearly shown in the relative spacing of the dots which are separated by a $1 \mathrm{~km}$ height interval. Generally, shear regions are separated by regions in which the wind changes very little and the dots are closely spaced on the plots. Another characteristic of the plots is the abrupt change in direction of the line joining the dots. Changes of $90^{\circ}$ or $180^{\circ}$ often occur and a reversal of direction may extend over a region of several $\mathrm{kms}$ or be confined to a height interval of only 2 or $3 \mathrm{~km}$.

A particularly noticeable characteristic of vapor trails is the distortion produced by regions of high wind shear. The results of a statistical analysis of the rate and frequency of occurrence of shears is shown in Figure 2. The shears from both North-South and East-West components of the winds were tabulated from the 29 observations. It is seen that shears up to $30 \mathrm{~m} / \mathrm{sec} / \mathrm{km}$ are frequently found throughout the altitude region 80 to $120 \mathrm{~km}$. Shears greater than $50 \mathrm{~m} / \mathrm{sec} / \mathrm{km}$ are infrequent and usually occur in the 100 to $110 \mathrm{~km} \mathrm{region}$. An exact rate for the high shears was not determined since they usually occur over small height intervals of less than a $\mathrm{km}$ and the measurement is very sensitive to small height errors.

Another characteristic of vapor trails is that generally, below about 110 $\mathrm{km}$, the trails are not smooth in appearance and expand at a rate greater than is expected from molecular diffusion. The irregularities appear in two distinct forms. Below about $100 \mathrm{~km}$, the appearance will be described as "stringy". Above 
品
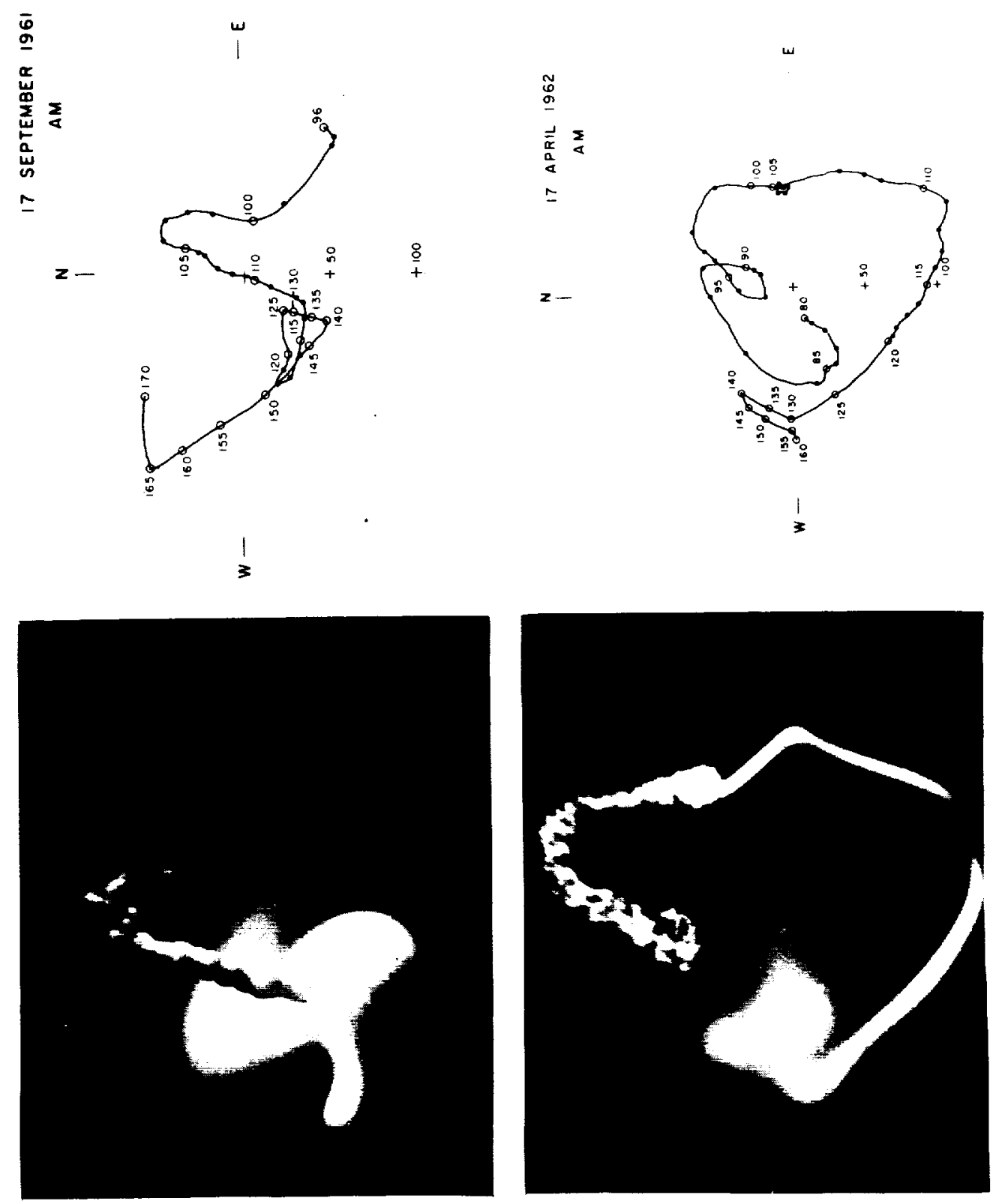

点点离占

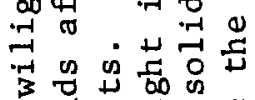

3 过

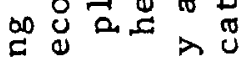

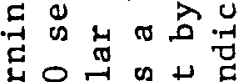

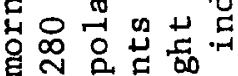

更

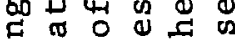

苛

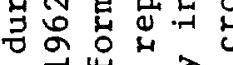

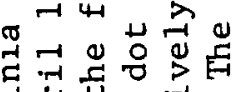

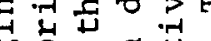

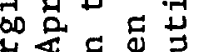

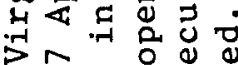

ज舟엉

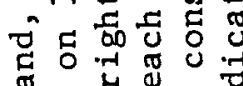

T. 40

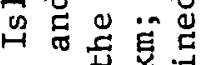

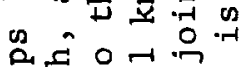

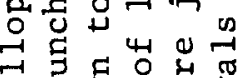

का हु०

$3-1$ 엉

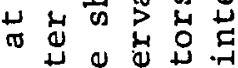

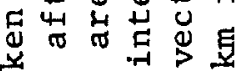

II

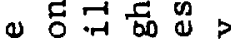

मे

उ क 낸ㄷ

40 ๑

出

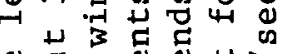

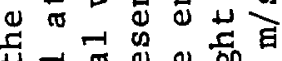
म

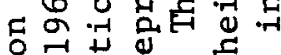

幽

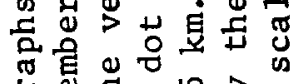

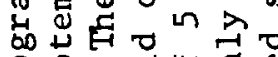
웡 o क : 品 क

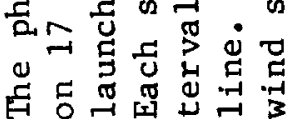

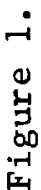




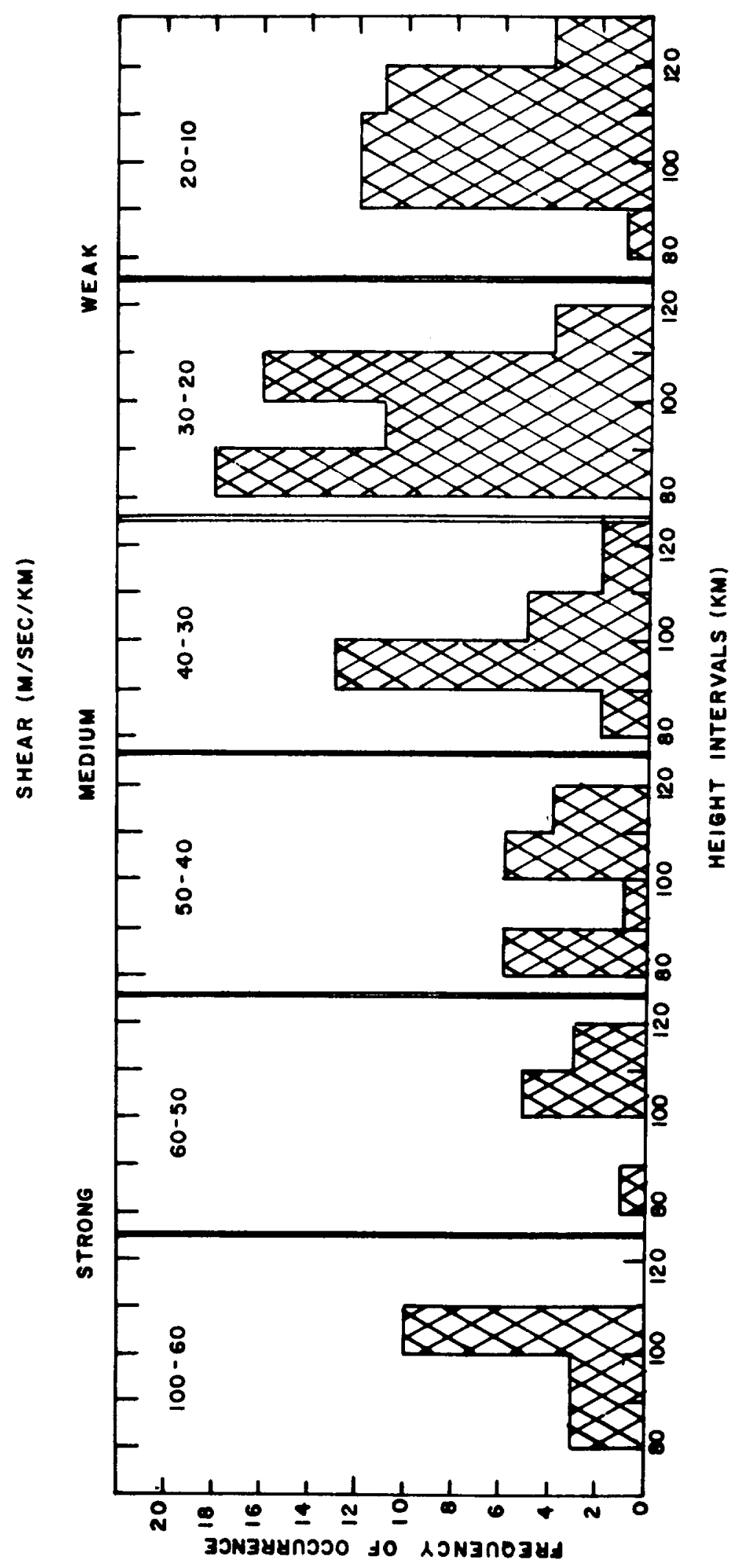

OD. 
this lower structure, another type of irregularity often occurs and will be termed "globular". An example of these types of trail irregularities is shown in Figures 1 and 3. This appearance is typical of most of the vapor trails, although all trails do not have as much "globular" structure. Generally, the "globules" occur in the region 100 to $110 \mathrm{~km}$ and may be present in any part or nearly all of this region. The "stringy" structure begins just below the "globules" and appears in most trails.

The presence of the "globules" is apparently independent of the wind shear at that height. They appear with about equal frequency at times when the shear is near zero as at times of high shear. The rate of growth of "globules" on several trails has been measured. The increase in radius is observed to be linear with time at a rate of 3 to $5 \mathrm{~m} / \mathrm{sec}$. The rate is independent of altitude and is constant for as long as observations are possible. The observed radii of one "globule" at various times are shown in Figure 3. Similar growth has been observed for the "stringy" structure, although measurement is difficult due to the irregular appearance of the trail. In regions where specific features could be identified for long periods of time, the radius of the trail increases at a steady rate of $3 \mathrm{~m} / \mathrm{sec}$. The rate of growth and frequency of occurrence does not appear to be dependent on wind shear.

It should be remembered that the preceding description concerns the appearance of a trail of sunlit alkali vapor and does not necessarily pertain to ambient atmospheric motions. It has not yet been shown that this irregular appearance of the trail is due entirely to an ambient atmospheric phenomena, such as turbulence. 


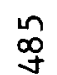
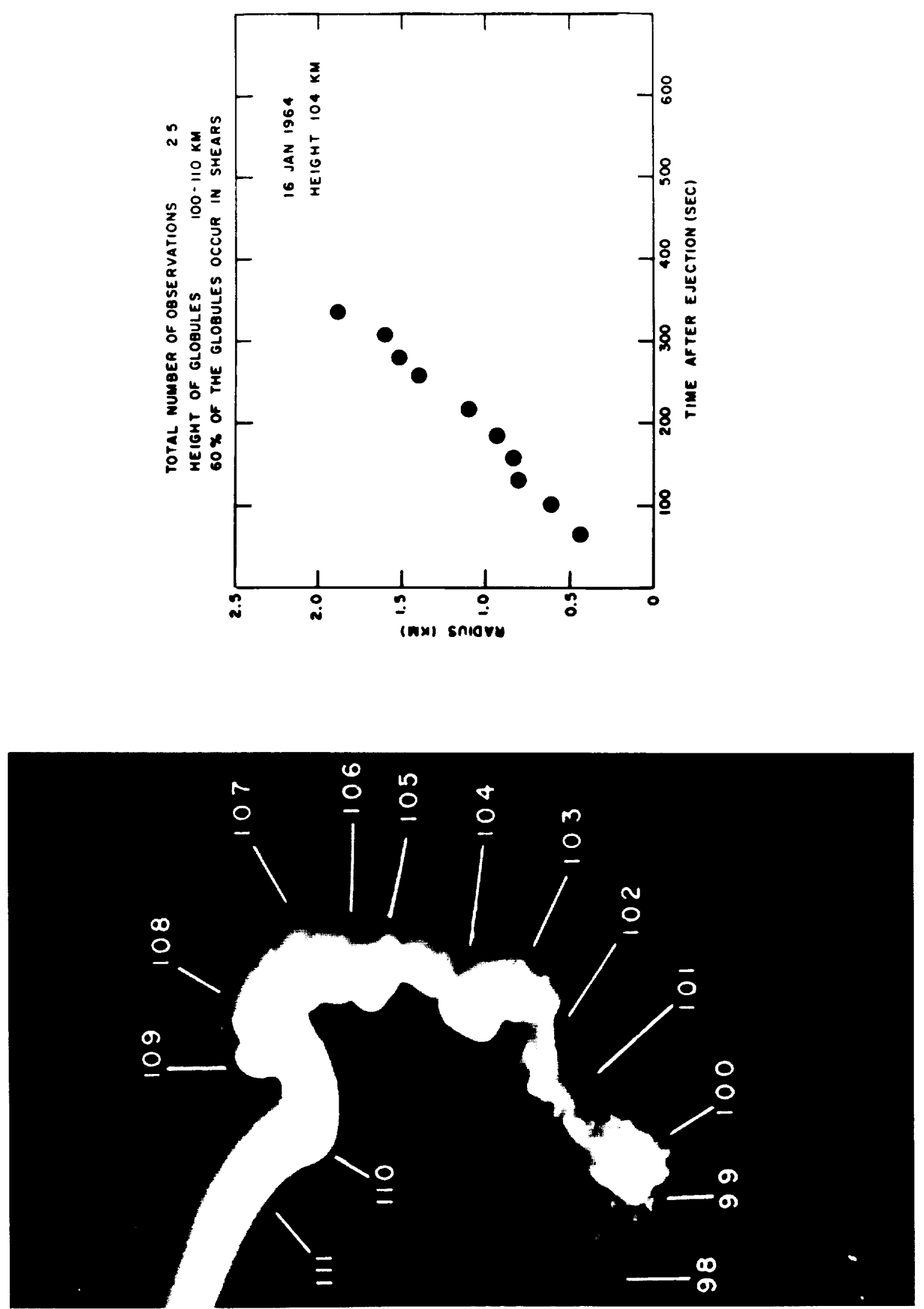

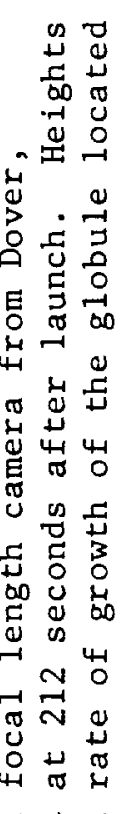

预吉告

过究芒

思

$\pi \vec{~}$

두

36 站

덤눙

$\frac{x}{\pi}$

ษั

is

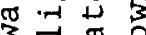

.

4 吾

व

Q

过苟

도ㅇㅛㅛㅇㅝ

ᄃ

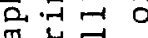

0 工

क⿺ 万丂

ㅇ

$\pm \infty$

, 3 .

组

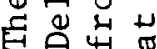

$\dot{m}$

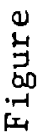


$=$ 


\section{CORRELATION OF WINDS AND PEAKS OF ELECTRON DENSITY}

On seven different occasions, observations of the wind profile were obtained from a vapor trail and nearly simultaneously measurements of the electron density profile were obtained with a Langmuir probe [4]. Five of the sets of observations were made using two rockets fired a few minutes apart along similar trajectories. Two sets were obtained with one rocket in which probe measurements were made during the ascent of the rocket and a vapor trail was deposited on the descent. The wind profiles obtained at these times are shown in Figures 4 through 10. The geomagnetic East-West component of the wind is plotted as a solid line and the geomagnetic North-South component is shown by a dotted line. Regions of enhanced electron density are marked by arrows on both components. The time difference, $\mathrm{T}$, in minutes and the horizontal distance, $\mathrm{R}$, in $\mathrm{kms}$ which separated the two measurements are also shown on each set of observations. In most cases the vapor trail could be observed for about 10 minutes and no changes in the winds were measured during this period.

The ionospheric sounding station at Wallops Island, Virginia, made continuous observations during all of the probe and wind measurements. The ionosonde records indicated a stable $\mathrm{E}$ layer throughout the period required for both measurements in al1 cases except 7 November 1962. At that time, the ionosonde was showing a primary sporadic $E$ layer at $120 \mathrm{~km}$ when the probe measurements were made, and at $100 \mathrm{~km}$ during the time of the wind observations. The probe showed large peaks at both heights as well as several others.

The arrows, denoting the peaks of the electron density profile, show that approximately half of the peaks occur within about 20 to $30 \mathrm{~m} / \mathrm{sec}$ of the zero point of an East-West shear. It should be noted that in some instances, the maximum wind velocity is not much greater than this value in the regions of interest. The other half of the arrows appear to be randomly placed with respect to shears. In all cases, the rate of the shears is 1 ess than $30 \mathrm{~m} / \mathrm{sec} / \mathrm{km}$, which value is frequently observed at this height.

Another method of plotting the data is shown in Figures 11 through 17 . The wind profiles are plotted as in Figure 1 and the positions of the peaks of the electron density profile are indicated by arrows in the center figure. Enlargements of these regions in which the extent and magnitude of the ionization peaks are indicated by dotted lines are also shown. It is seen that many of the peaks from the probe data may be associated with certain features of the wind profile. The peaks on the 7 November 1962 profile occur in regions where the direction of the joining line rapidly changes by $90^{\circ}$ or $180^{\circ}$. The largest peak occurred at $100 \mathrm{~km}$ where the wind velocity and shear was low, but the direction of the line joining the dots changed rapidly. The dotted line is not closed indicating the probe response was saturated over the region between the two arrows. Peaks at 107 and $121 \mathrm{~km}$ are also associated with rapid changes in direction on the plot. 


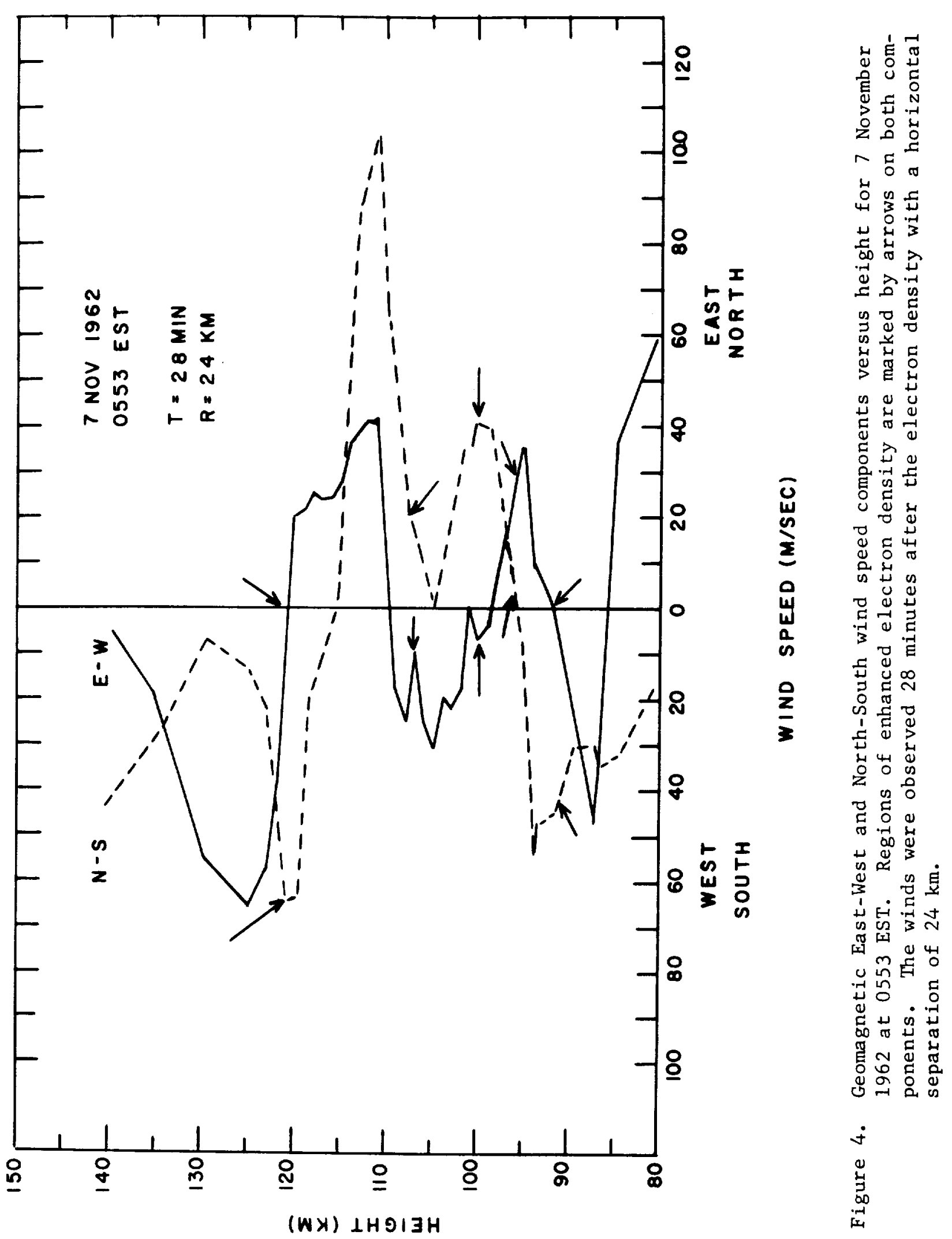




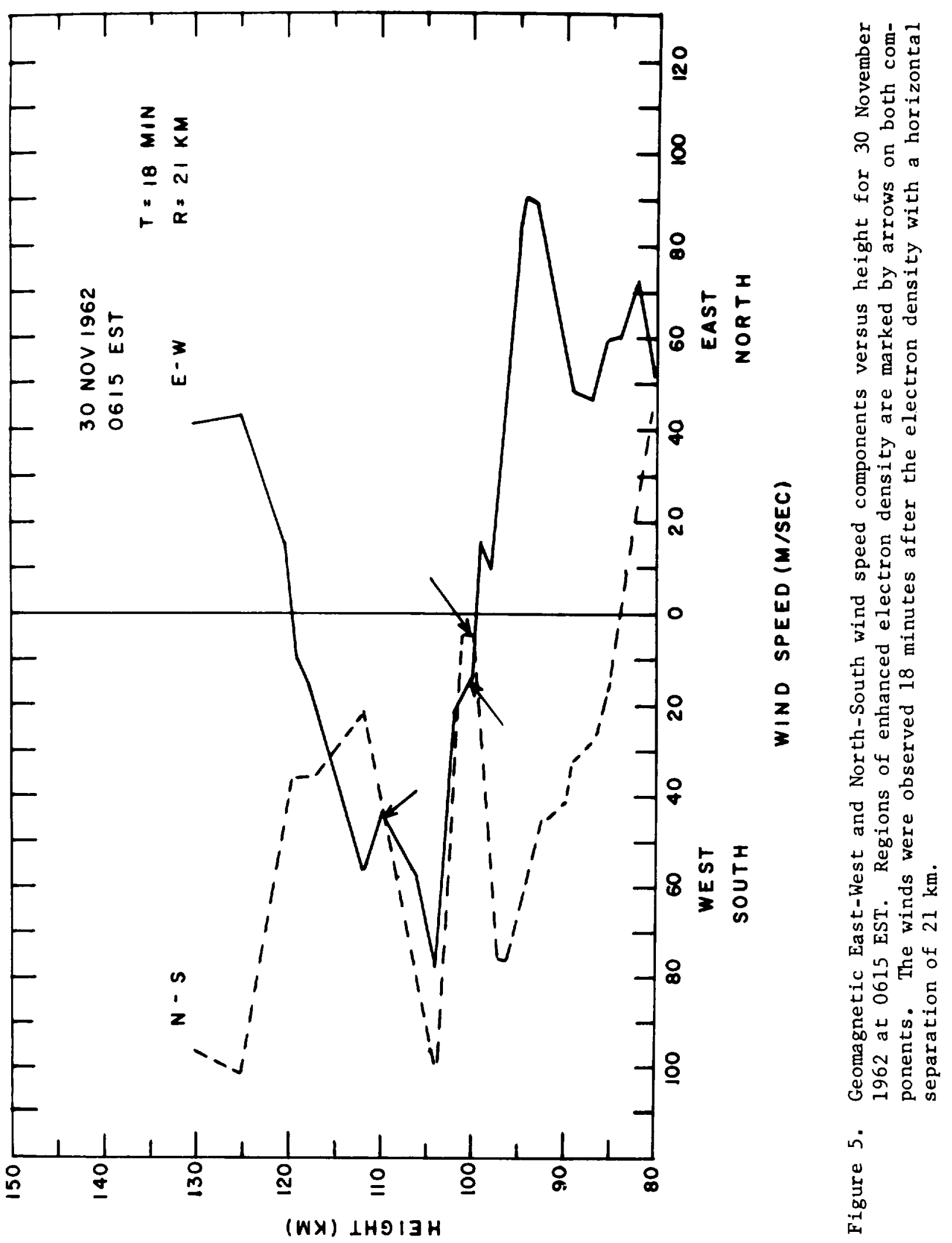




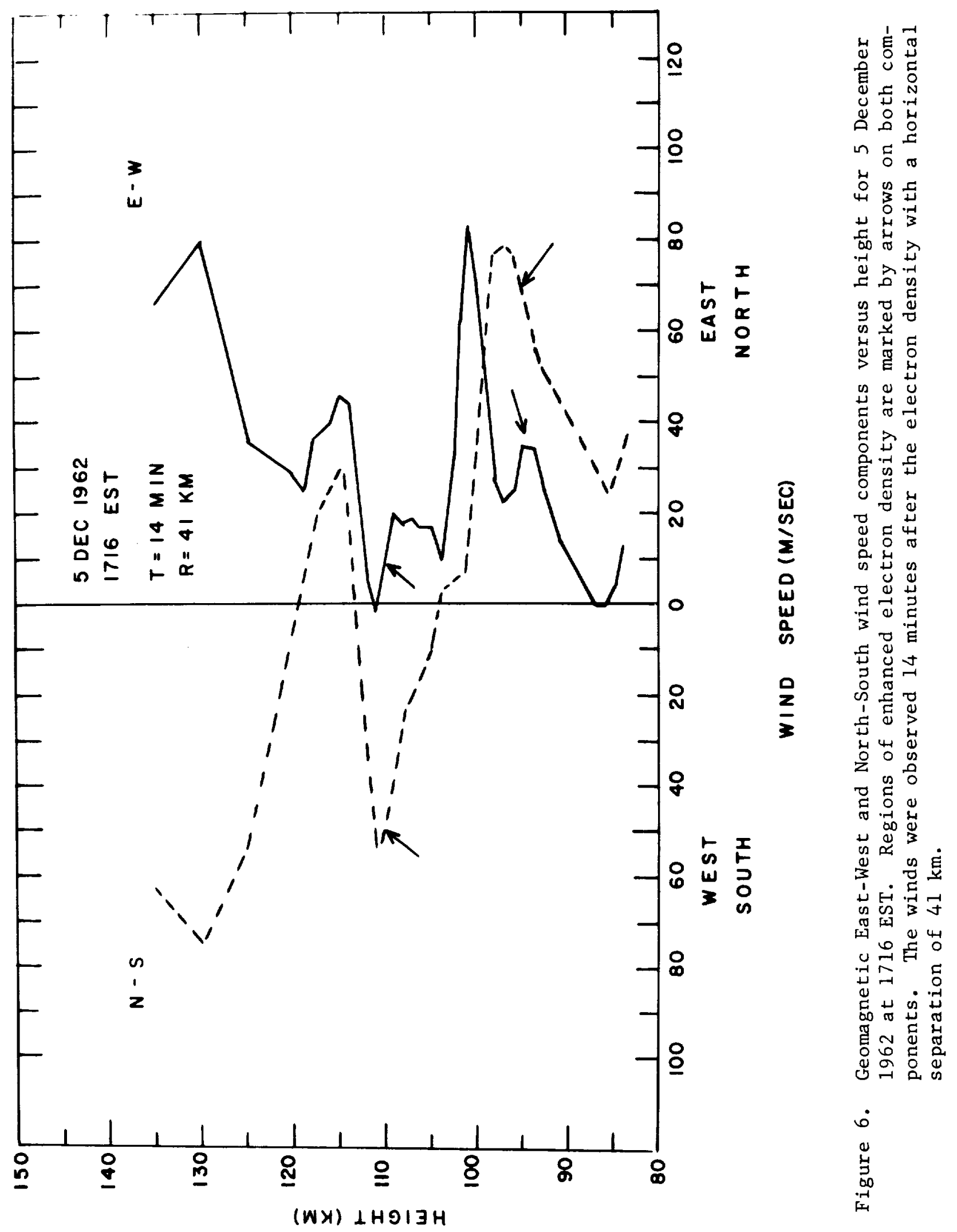




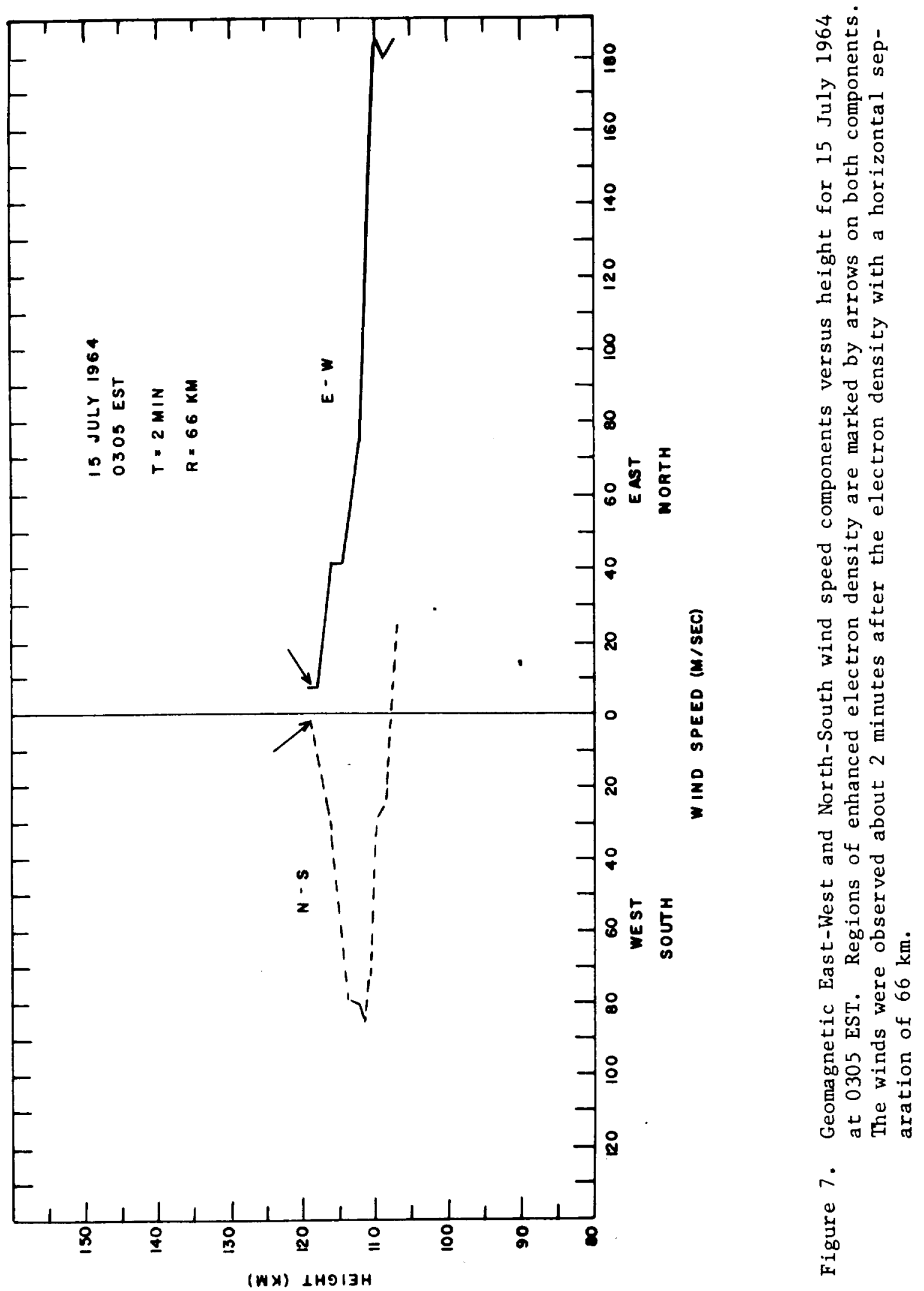




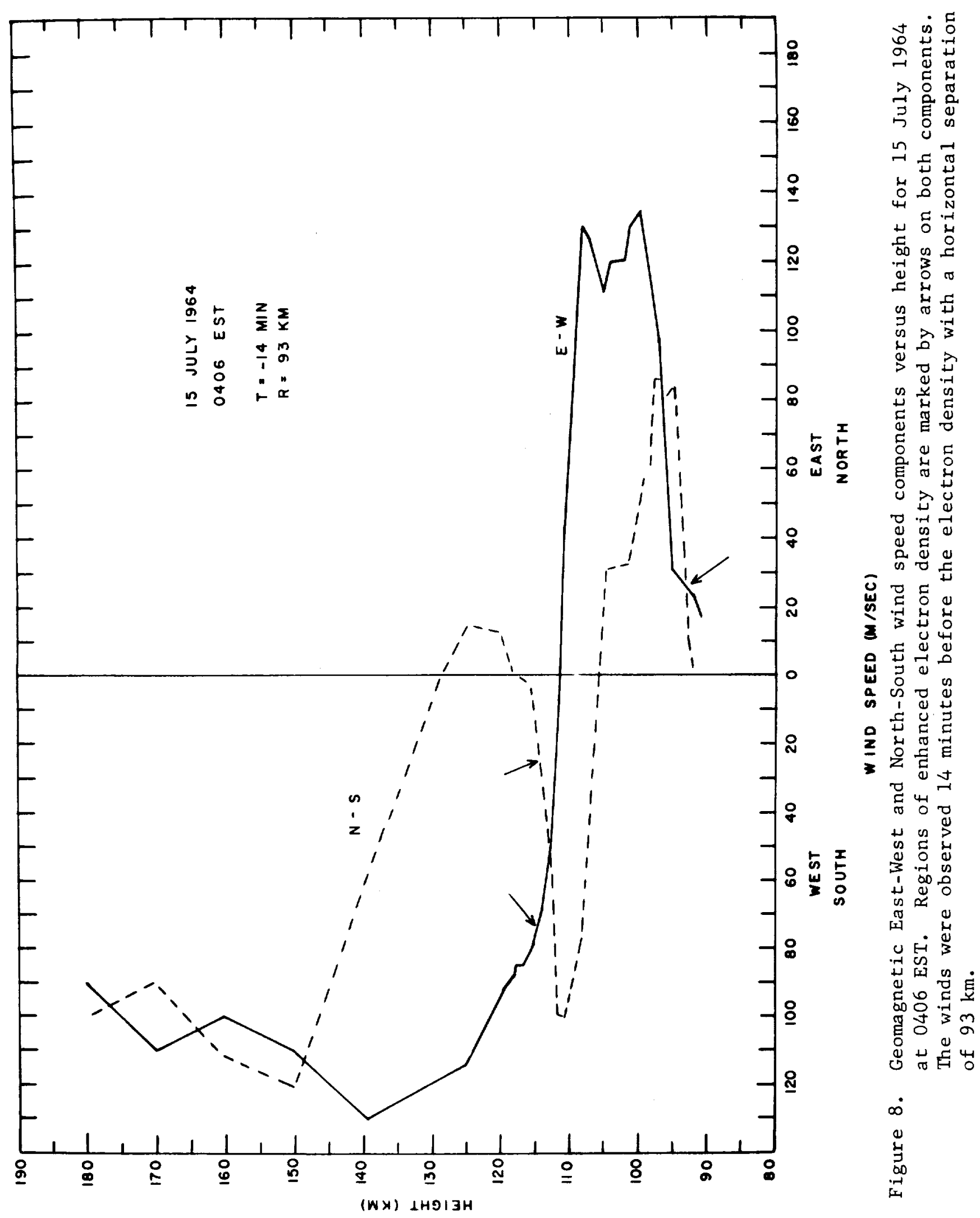




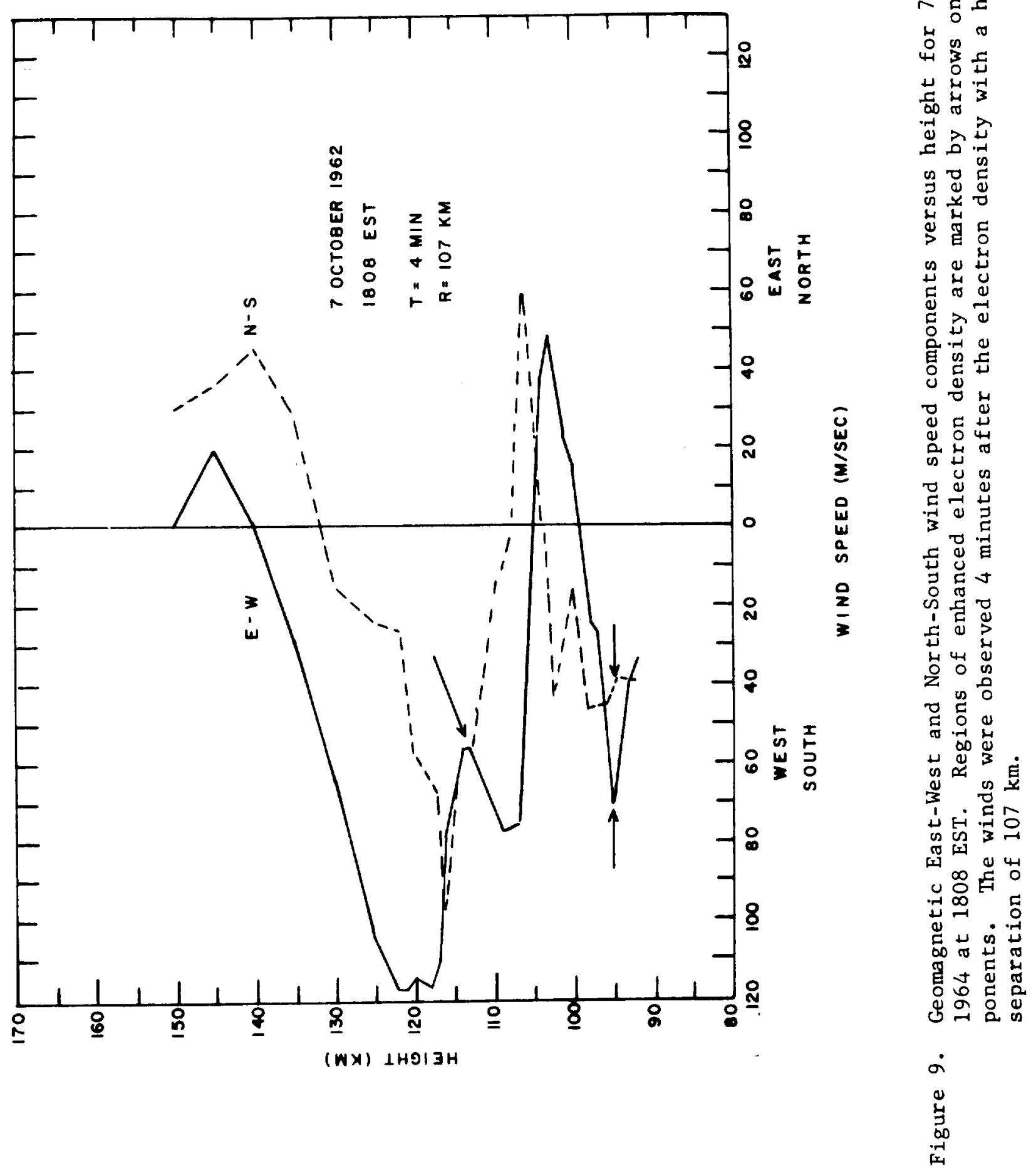




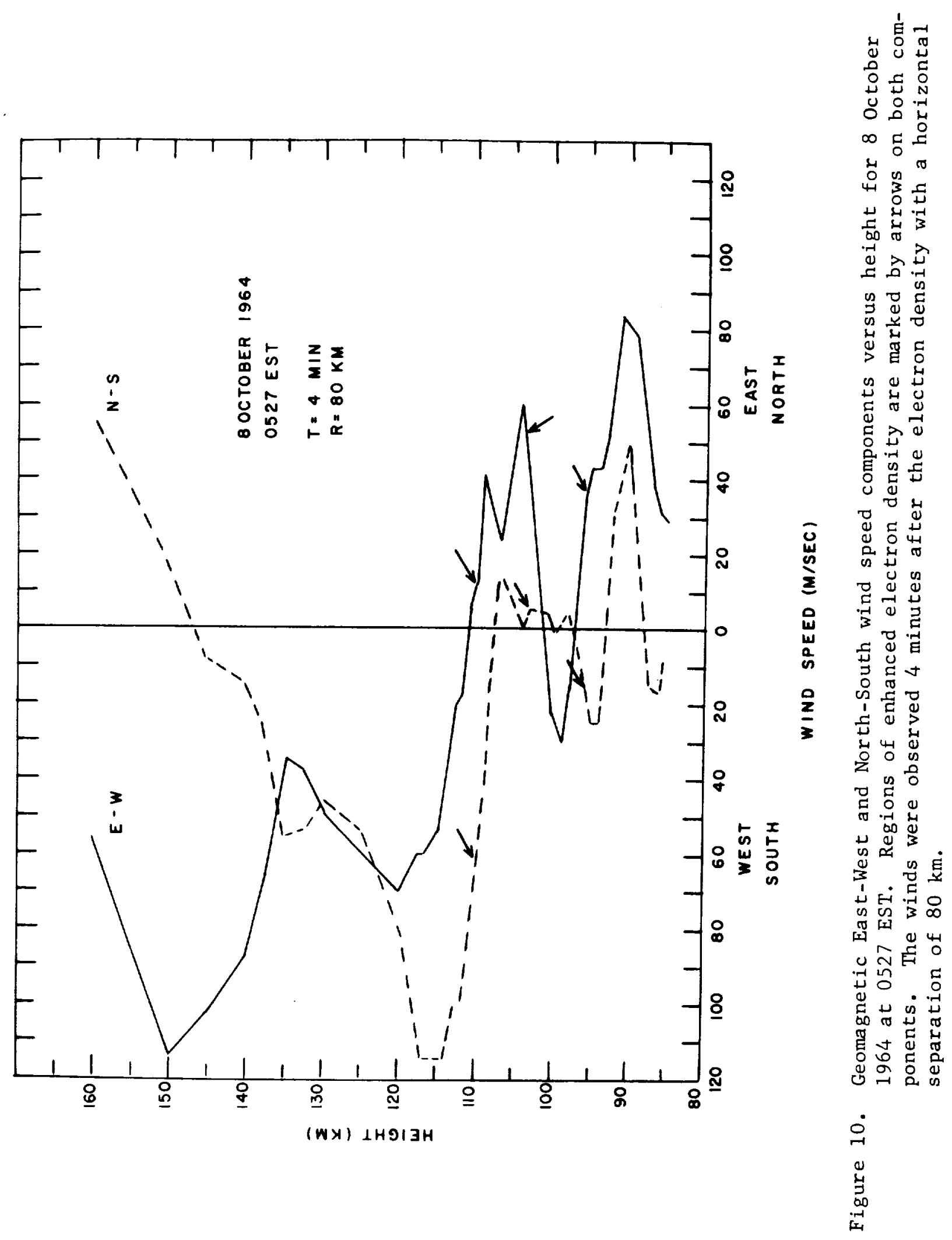




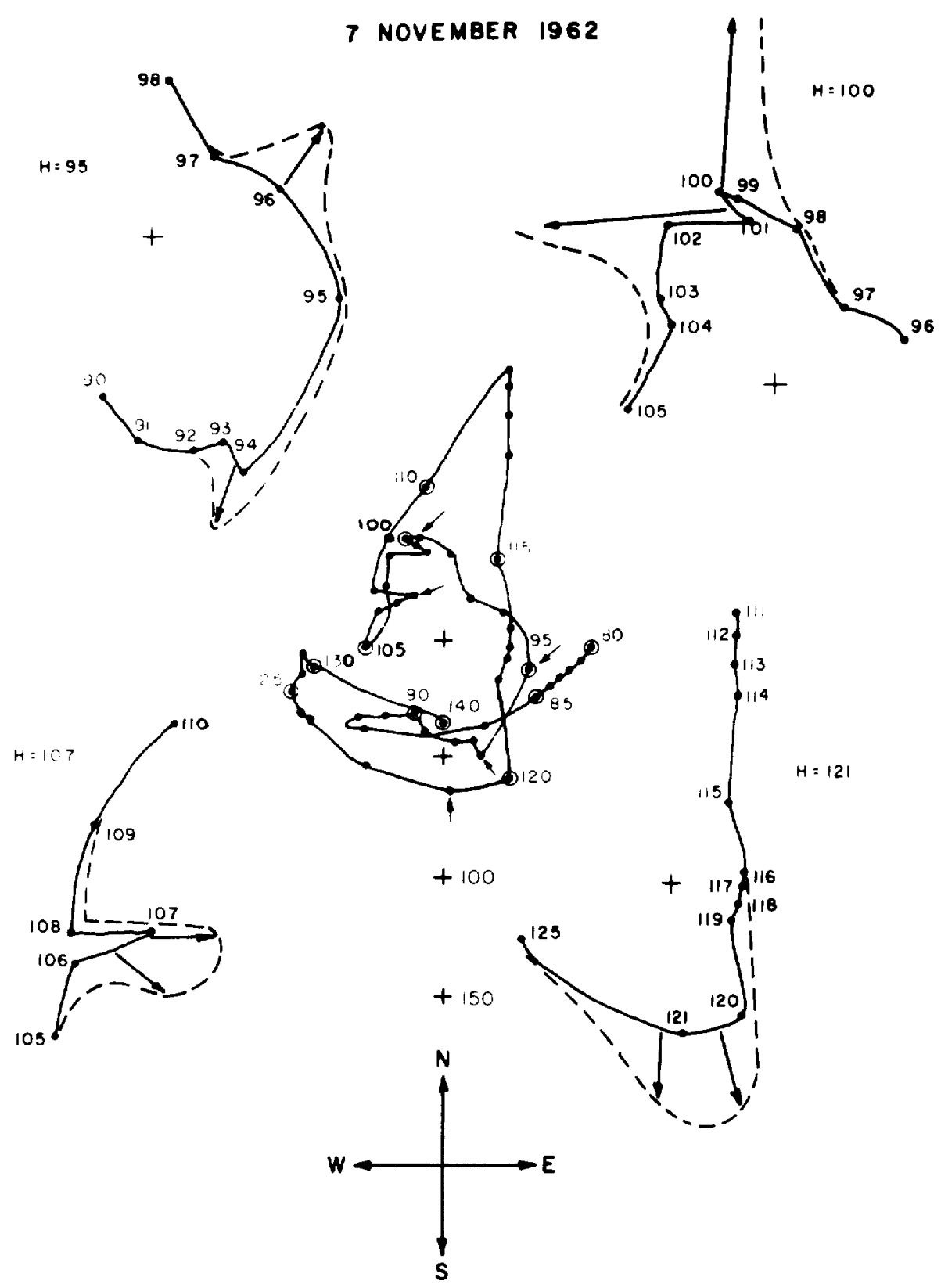

Figure 11. A polar plot of the wind profile for 7 November 1962 appears in the center. Solid dots mark the ends of the wind vectors for each $\mathrm{km}$ in height. The open circles indicate each $5 \mathrm{~km}$ height interval and are the only ones which show the height. The crosses indicate the wind speed scale in $\mathrm{m} / \mathrm{sec}$. Regions of enhanced electron density are marked by arrows. Each region of enhanced electron density is shown on a double wind speed scale. The dashed lines around the arrows represent the general region covered by the electron enhancement. The geographical compass directions are shown at the bottom of the figure. 


\section{NOVEMBER 196?}

\section{$\Delta M$}

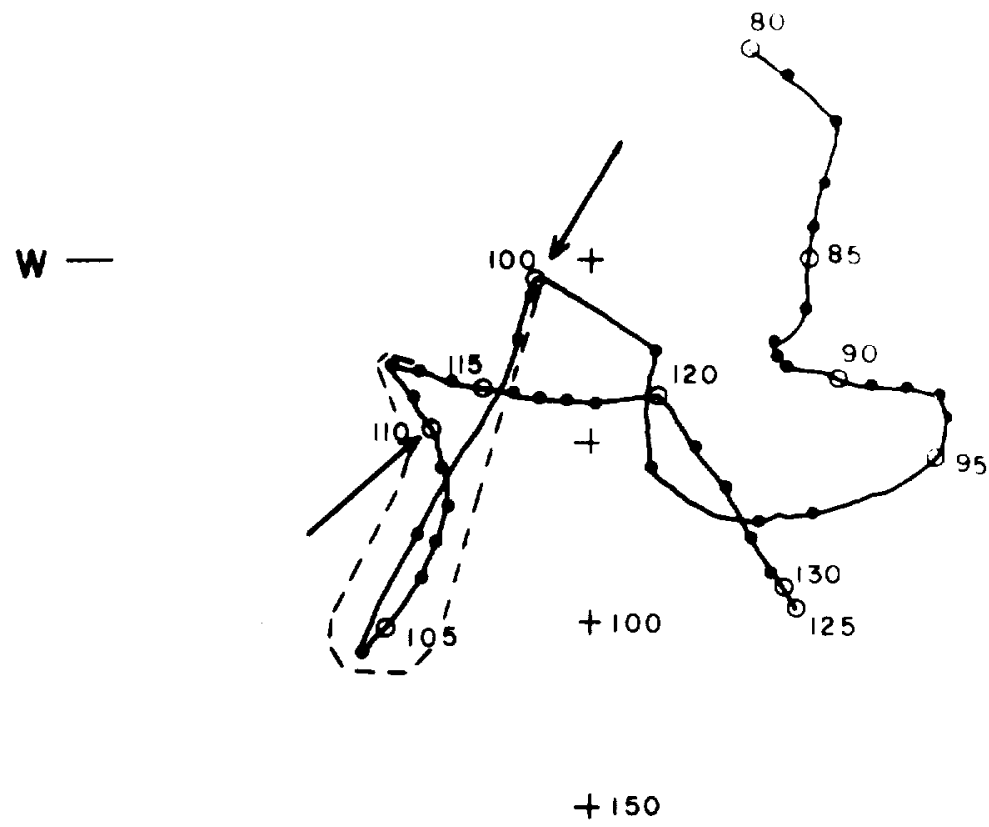

$+200$

Figure 12. A polar plot of the wind profile for 30 November 1962 is shown. The solid dots mark the ends of the wind vector for each $\mathrm{km}$ in height, and the open circles are for every $5 \mathrm{~km}$. The crosses represent the wind speed scale in $\mathrm{m} / \mathrm{sec}$. The arrows indicate regions of maximum enhanced electron density, while the dotted lines encompass the whole area. 
$H=95$
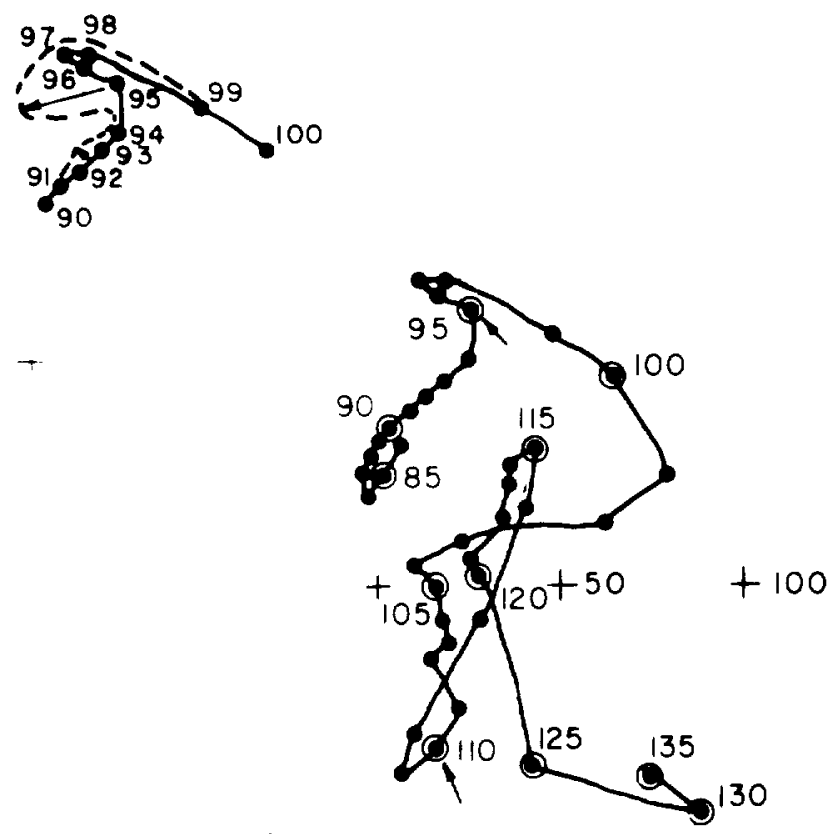

$H=110$

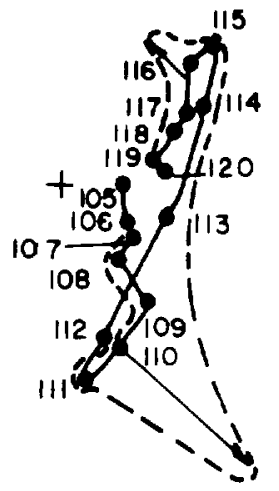

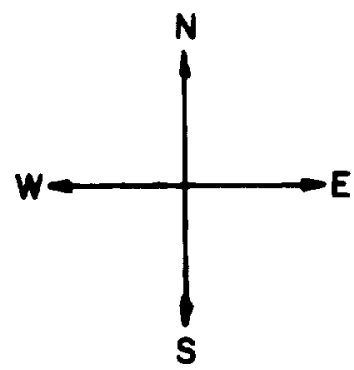

Figure 13. A polar plot of the wind profile for 5 December 1962 appears in the center. Solid dots mark the ends of the wind vectors for each $\mathrm{km}$ in height. The open circles indicate each $5 \mathrm{~km}$ height interval and are the only ones which show the height. The crosses indicate the wind speed scale in $\mathrm{m} / \mathrm{sec}$. Regions of enhanced electron density are marked by arrows. The two regions of enhanced electron density are shown separately to the side on the same scale. The dashed lines around the arrows represent the general region covered by the electron enhancement. The geographical compass directions are shown at the bottom of the figure. 


\section{JULY 1964}

\section{EST}

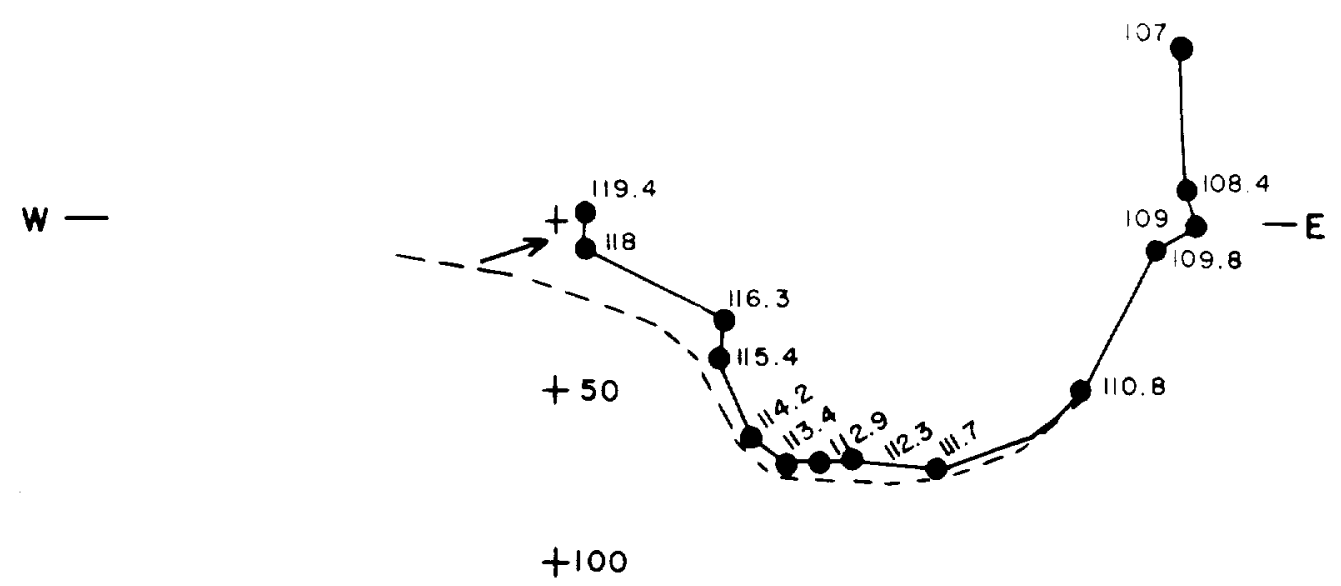

$+150$

$+200$

1

$\mathbf{S}$

Figure 14. A polar plot of the wind profile for $15 \mathrm{July} 1964$ at 0305 EST is shown. Since this was a night shot the sodium cloud appeared only between the heights of 107 to $119.4 \mathrm{~km}$. The solid dots mark the ends of the wind vectors with the accompanying heights. The crosses indicate the wind speed scale in $\mathrm{m} / \mathrm{sec}$. The arrow represents the position of the maximum electron density peak at $119 \mathrm{~km}$. The dashed line shows the general region covered by the electron enhancement, and is shown incomplete due to the wind profile limitations. 

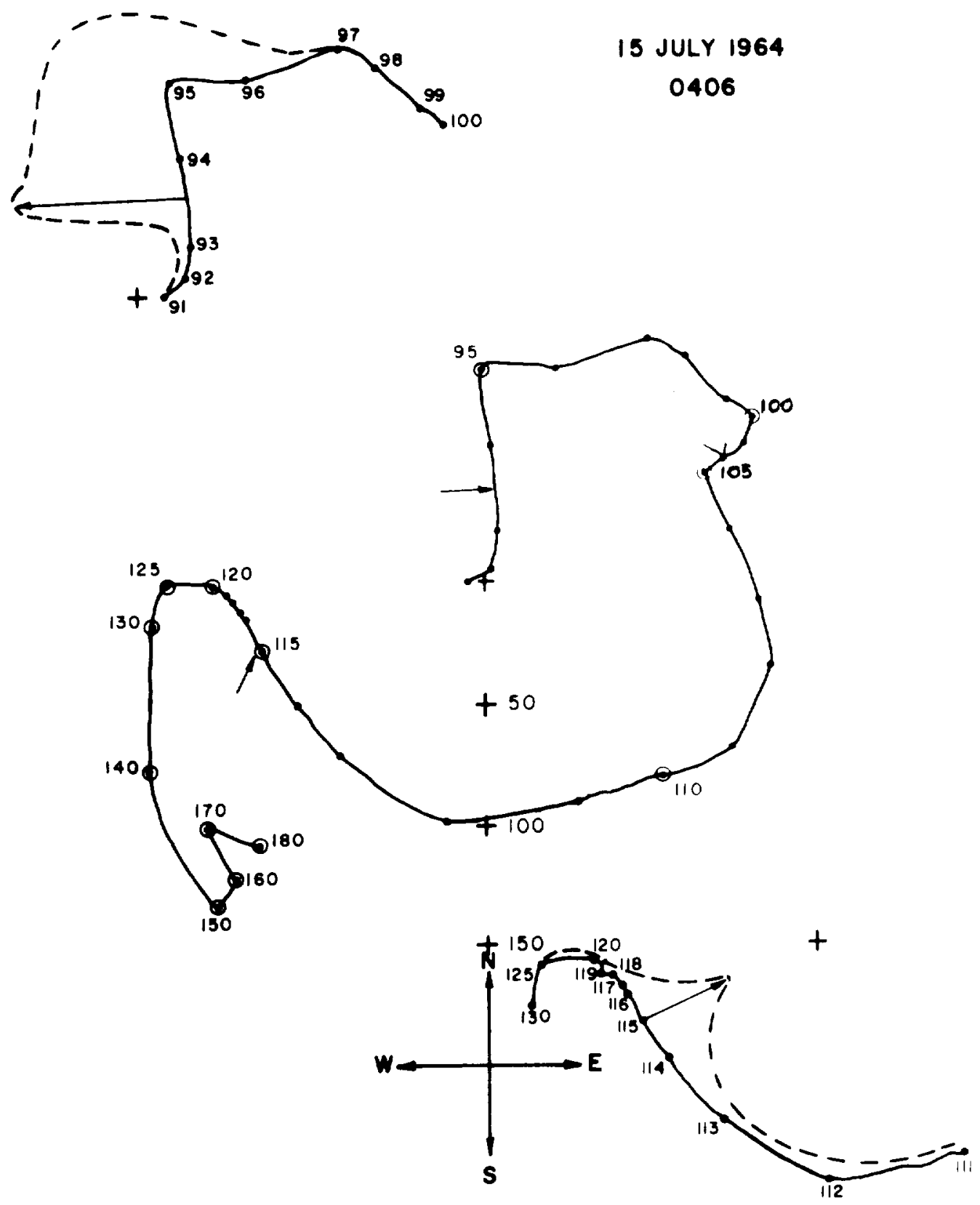

Figure 15. A polar plot of the wind profile for 15 July 1964 at 0406 EST appears in the center. Solid dots mark the ends of the wind vectors for each $\mathrm{km}$ in height. The open circles indicate each $5 \mathrm{~km}$ height interval and are the only ones which show the height. The crosses indicate the wind speed scale in $\mathrm{m} / \mathrm{sec}$. Regions of enhanced electron density are marked by arrows. The two regions of enhanced electron density are shown separately to the side on the same scale. The dashed lines around the arrows represent the general region covered by the electron enhancement. The geographical compass directions are shown at the bottom of the figure. 
A magnetic storm was in progress during the observations of 30 November. High electron densities were observed over the region 100 to $110 \mathrm{~km}$ with slight peaks at the extremes. This entire region is associated with a region of reversal in direction on the plot in which the rate of shear is relatively high in one direction and low in the other.

Both of the peaks of the 5. December probe measurements occur in regions of rapid directional change. The wind observations at $0305 \mathrm{EST}$ on $15 \mathrm{Ju} 1 \mathrm{y}$ did not include the entire height range and thus results are inconclusive. One of the peaks at $0406 \mathrm{EST}$ on $15 \mathrm{Ju}$ ly is associated with a directional change on the plot. The upper peak occurs where a region of high shear ends and a region of low shear begins. Both of the peaks of 7 October and two of the three peaks of 8 October also may be associated with regions of sharp directional change on the plot.

In summary, it is demonstrated that of 17 observed peaks in the electron density profiles, 14 of these may be associated with rapid directional changes in the plot joining the end points of the wind vectors; 2 of these apparently are not so related; and 1 is inconclusive. It should also be noted that there are often more regions of directional change than there are peaks on the electron density profile. Thus, this particular wind structure is not a sufficient condition for formation of an ionized layer.

The value of a statistical analysis for such a small sample is dubious, and the proper method of approach is uncertain. If the incomplete wind profile of $0305 \mathrm{EST}$ on $15 \mathrm{July}$ is omitted, the total number of bends occurring between 90 and $120 \mathrm{~km}$ on the other six profiles is 29 . The total number of ionization peaks in the same regions is 16 . The numbers of each feature are shown in Table 1. Most of the ionization peaks occurred within less than two kilometers of the associated features on the wind profile. However, if we assume that the ionization peaks and wind features need only be contained within a height range of $3 \mathrm{~km}$, which is the average half-width of the ionized layers, the total region may be divided into $(30 / 3) \times 6=60$ layers, half of which may contain a wind feature. Then it would be expected that half of the ionization peaks could be associated with a wind feature. Actually this percentage is about $90 \%$. Other methods of analysis can give wide variation in the expected relationships. For instance the probability is extremely small that each of five ionization peaks in the 7 November 1962 observations would be associated within one kilometer with one of seven wind features.

The line joining two adjacent dots in the plots is the vector representing the difference in wind velocity over a $1 \mathrm{~km}$ height interval. The rapid directional changes on the plots are due to changes in direction of these difference vectors. Thus, it is implied that the regions of enhanced electron density are 
TABLE 1

THE NUMBER OF BENDS AND IONIZATION PEAKS OCCURRING BETWEEN

90 AND $120 \mathrm{KM}$ FOR EACH SET OF OBSERVATIONS

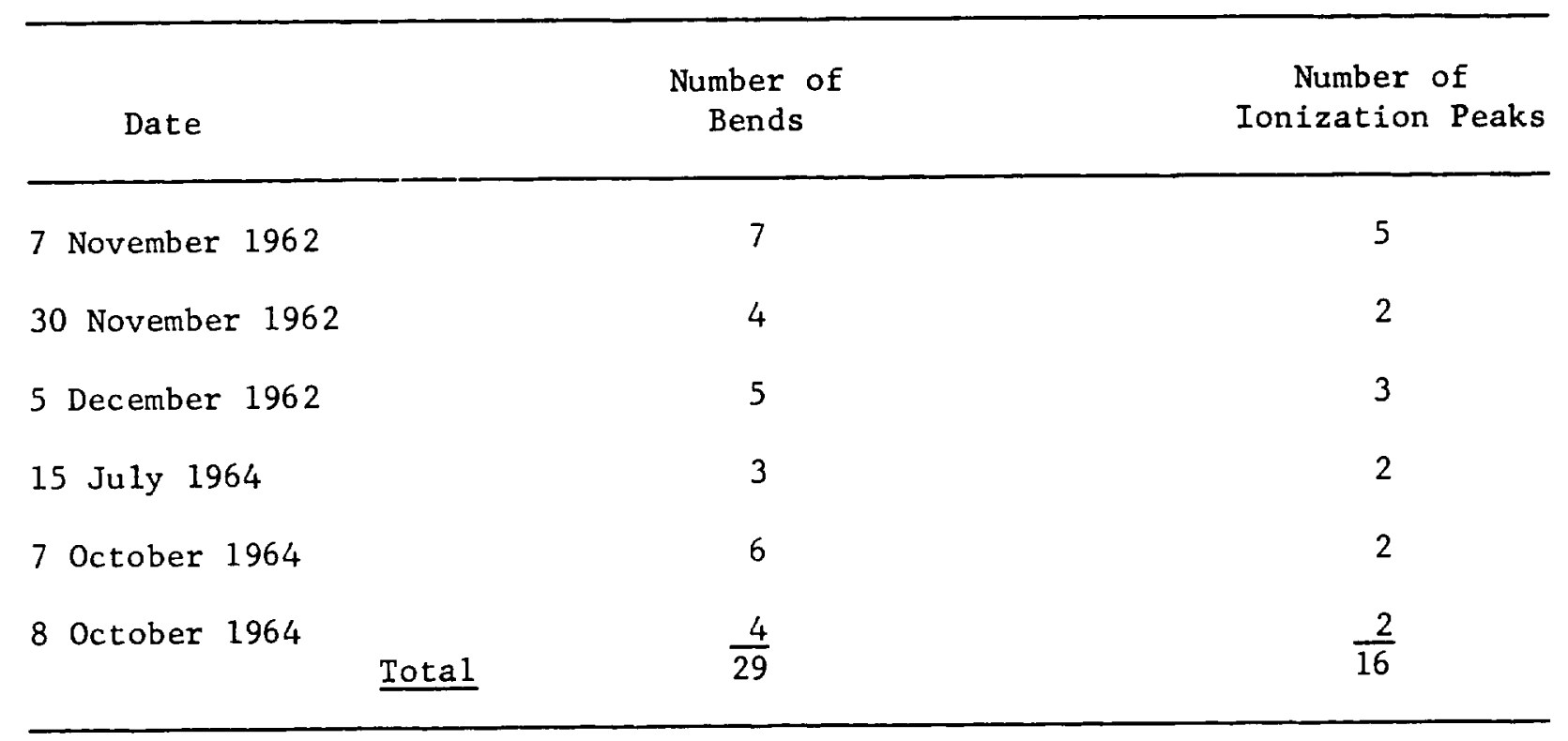


$\ddots$

-

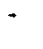

- 
1. Manring, E., Bedinger, J. and Knaflich, H., Some Measurements of Winds and of the Coefficient of Diffusion in the Upper Atmosphere, Space Research II, Proceedings of the Second International Space Science Symposium Florence, April 10-14, 1961, pp.1107-1124 (edited by H. C. van de Hulst, C. de Jager, and A. F. Moore, North-Holland Publishing Co., Amsterdam) (1961).

2. Manring, E., Bedinger, J. and Knaflich, H., "Measurements of Winds in the Upper Atmosphere during Apri1 1961," J. Geophys. Res., 67, No. 10, $3923-$ 3925 (1962).

3. Smith, L. G., "Rocket Observations of Sporadic E and Related Features of the E Region," Radio Sci. (J. Res. Nat1. Bur. Std., Section D) (to be published). 


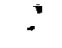

-

" 